\title{
High-Speed Compact Entry Capsule Enhanced by Lightweight Ablator and Crushable Structure
}

\author{
By Tetsuya YamadA, ${ }^{1)}$ Toshio Ogasawara, ${ }^{2)}$ Koichi KitAzonO ${ }^{3)}$ and Hideyuki TAnNo ${ }^{4)}$

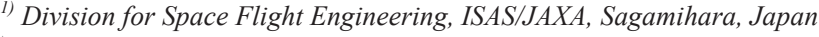 \\ 2) Aerospace Research and Development Directorate, JAXA, Mitaka, Japan \\ ${ }^{3)}$ Tokyo Metropolitan University, Hachioji, Japan \\ 4) JAXA Kakuda Space Center, Kakuda, Japan
}

(Received August 8th, 2015)

\begin{abstract}
Recently, target bodies of the solar exploration extended to distant heavenly bodies beyond the Mars, and even to more distant ones. Because the overall mission duration tends to be longer and longer in such high-energy missions, reliability requirements for the subsystems become severer. In case of sample return missions from the distant asteroids, the earth entry velocity of the sample return capsule is often estimated to exceed $14 \mathrm{~km} / \mathrm{s}$, or reach to $15 \mathrm{~km} / \mathrm{s}$, and the overall mission duration also exceeds 10 years, or approaches to 20 years in some cases such as sample return from distant comets. The high-speed compact entry capsule is one of the key technologies to accomplish such challenging missions. Two of the important issues concerned with the high-speed entry capsules are severe thermal protection in the high-speed entry and secure functional reliability of the overall slow-descending sub-systems at the very final phase of the mission. The present study shows a conceptual design of the high-speed compact entry capsule enhanced by state-of-the-art technologies of the lightweight ablator and the crushable structure. The lightweight thermal protection ablator is very advantageous for reducing the ballistic coefficient and the heatflux during reentry. Three-dimensionally woven lightweight ablator has exhibited excellent recession characteristics under the $12 \mathrm{MW} / \mathrm{m}^{2}$ arc-heating tests. The crushable structure realizes chuteless landing by absorbing landing shock energy and protects the instrument modules against the landing shock within a prescribed deceleration level. The chuteless landing is advantageous for secure decent system in that ignition electronics, parachutetriggering sensors, and triggering-control logic circuits etc. are no longer required.
\end{abstract}

Key Words : Small Body Exploration, Reentry, Capsule, Ablator, Crushable Structure

\section{Nomenclature}

A : area normal to the acceleration $\mathrm{V}_{0} \quad$ : total volume of the crushable material

$\mathrm{m}_{0,} \mathrm{~m}_{\mathrm{sq}} \quad$ : total mass, mass of squashed region

$\mathrm{m}_{\mathrm{p}}, \mathrm{m}_{\mathrm{c}} \quad$ : mass of payload, crushable material

$\mathrm{v} \quad$ : velocity at landing

$\mathrm{y} \quad$ : position in acceleration direction

$\mathrm{y}_{0}, \mathrm{y}_{\mathrm{s}} \quad$ : initial position, position of squashed region

$\varepsilon, \varepsilon_{2} \quad: \quad$ stain, plateau-end strain

$\rho_{c} \quad: \quad$ crushable material density

$\sigma, \sigma_{p} \quad: \quad$ stress, plateau stress

\section{Introduction}

Recent years, target heavenly bodies of the solar exploration extended to distant bodies beyond the Mars, and even to more distant ones. Because the overall mission duration tends to become longer and longer in such highenergy missions, reliability requirements for the subsystems become severer. In case of sample return from the distant asteroids, the earth entry velocity is often estimated to exceed $14 \mathrm{~km} / \mathrm{s}$, or reach to $15 \mathrm{~km} / \mathrm{s}$, and the overall mission duration also exceeds 10 years, or approaches to 20 years in such sample returns as from distant comets ${ }^{1), 2)}$. The highspeed compact entry capsule is one of the key technologies to accomplish such challenging missions. Two of the important issues concerned with the high-speed entry capsules are severe thermal protection in the high-speed entry and secure functional reliability of the total slow-descending subsystems at the very final phase of the mission ${ }^{3}$.

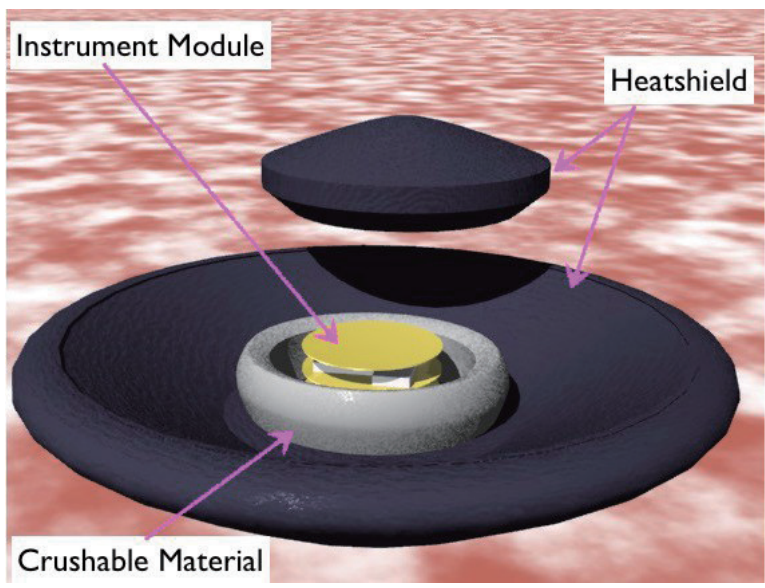

Fig. 1. Artist's impression of a small low-ballistic coefficient capsule with instrument module surrounded by the crushable material. 
Entry capsules with small ballistic coefficient, as schematically shown in Fig. 1, generally reduce the maximum total heat flux at the constant entry velocity, the convective heatflux is decreased while the radiative partly increased. The lightweight thermal protection ablator is very advantageous for reducing heatflux by the effect of the small ballistic coefficient of the total entry vehicle. Moreover the severe flight environment, especially the impact pressure on the capsule requires high structural strength for the thermal protection material for minimizing total recession of the material. Both characteristics of lightweight and higher allowable stress of the material is necessary.

The crushable structure is expected to realize parachuteless landing by absorbing landing shock energy and to protect the instrument modules against the landing shock within a prescribed level, which technology is advantageous for secure decent system in that ignition electronics, parachute-triggering sensors, and triggeringcontrol logic circuits etc. are no longer required.

The Hayabusa sample return capsule (SRC) have passed through the excessively severe high aerodynamic heating of about $14 \mathrm{MW} / \mathrm{m}^{2}$ and successfully recovered after slowdescent by the parachute. The compact capsule's technologies of the Hayabusa SRC will be no longer applicable to such high-speed reentry missions described above without technological progress added to them, which should be extended and evolved through development of the high-speed entry missions.

The present study shows a conceptual design of the high-speed compact entry capsule enhanced by state-of-theart technologies of the lightweight ablator and the crushable structure with brief description of development status of them.

\section{High-speed Missions and Compact Capsule}

\subsection{Issues on high-speed entry missions}

Issues concerned with the high-speed earth reentry missions up to $15 \mathrm{~km} / \mathrm{s}$ are summarized as follows;

1) Precise prediction of the heatflux, especially of the radiative heatflux, in the highly ionized flow that is not experienced or simulative in the ground test facilities.

2) Understanding of thermochemical behavior of the TPS material in the high-enthalpy flow and its development.

3) high reliability of the subsystem devises for long term missions.

Because the high energy mission essentially defies launch capability, the weight budget allocated to SRC is very limited, and the capsule required to adopt compact design both in weight and size.

Moreover, important issues related to the high-energy missions to be pointed out here is long mission duration: For example, round trip over 20 years are planned in the Trojan asteroid sample return mission ${ }^{4}$. Until now in the final phase of the mission, the small capsule needed to deploy parachute at the appropriate altitude, which requires functionally perfect conditions of the descent subsystems

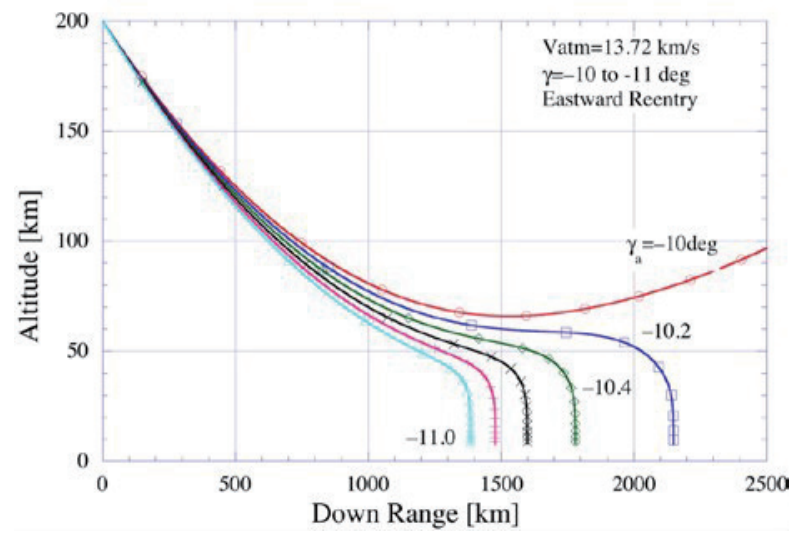

Fig. 2. Marco-Polo SRC (2006) flight (altitude vs. down range characteristics with parameters of flight path angle).

Table 1. Total heatflux as a function of nose radius (Rn) and front surface area (S) at Hayabusa similar shape and weight.(16.5 kg weight, $14.8 \mathrm{~km} / \mathrm{s}$ entry, FPA=10.3)

\begin{tabular}{|c|c|c|c|c|}
\hline & $\mathrm{Rn}=0.20 \mathrm{~m}$ & 0.22 & 0.24 & 0.25 \\
\hline $\begin{array}{c}\mathrm{S}=0.12 \mathrm{~m}^{2} \\
(\Phi 40 \mathrm{~cm})\end{array}$ & 20.4 & 19.9 & 19.5 & 19.3 \\
\hline $\mathrm{S}=0.14 \mathrm{~m}^{2}$ & 18.9 & 18.5 & 18.0 & 17.8 \\
\hline $\mathrm{S}=0.16 \mathrm{~m}^{2}$ & 17.7 & 17.3 & 16.8 & 16.7 \\
\hline $\mathrm{S}=0.18 \mathrm{~m}^{2}$ & 16.7 & 16.2 & 15.8 & 15.7 \\
\hline $\begin{array}{c}\mathrm{S}=0.20 \mathrm{~m}^{2} \\
(\Phi 50 \mathrm{~cm})\end{array}$ & 15.8 & 15.4 & 15.0 & 14.8 \\
\hline $\mathrm{S}=0.22 \mathrm{~m}^{2}$ & 15.0 & 14.7 & 14.2 & 14.1 \\
\hline
\end{tabular}

and devises such as timers, acceleration sensors, ignition circuits, batteries, and control logic FPG board etc. It is a most difficult task to guarantee the functional safety of overall descending subsystems in about 20 years' orbital flight after the launch. The descending systems that lead to the complete loss of mission purposes must be free from functional malfunctions except trivial material degradation.

\subsection{High-speed compact capsule design philosophy}

On designing of the thermal protection system (TPS), the characteristics of the TPS material are one of the design drivers, the surface recession characteristics becomes more important in the high-speed missions. On developing thermal protection material, it will be important to carry out heating test with the same heatflux level as the flight environment in order to minimize the design extrapolation. Surveying the world's arc windtunnel facility, it will be a tacit understanding that operations with the heatflux over 15 to $20 \mathrm{MW} / \mathrm{m}^{2}$ level are difficult (may not be impossible). Thus, from design safety perspective, it is desirable to suppress the heatflux in the entry mission within the simulation limitation by the ground test facilities. Though it is one of the solutions to adopt the shallow flight path angle (FPA) at the entry condition in order to reduce the maximum heatflux, the FPA allowable for the high-speed entry tends to be steep for the sake of secure capture in the atmosphere up to $10.2^{\circ}$ as shown in Fig. 2, and shallow 

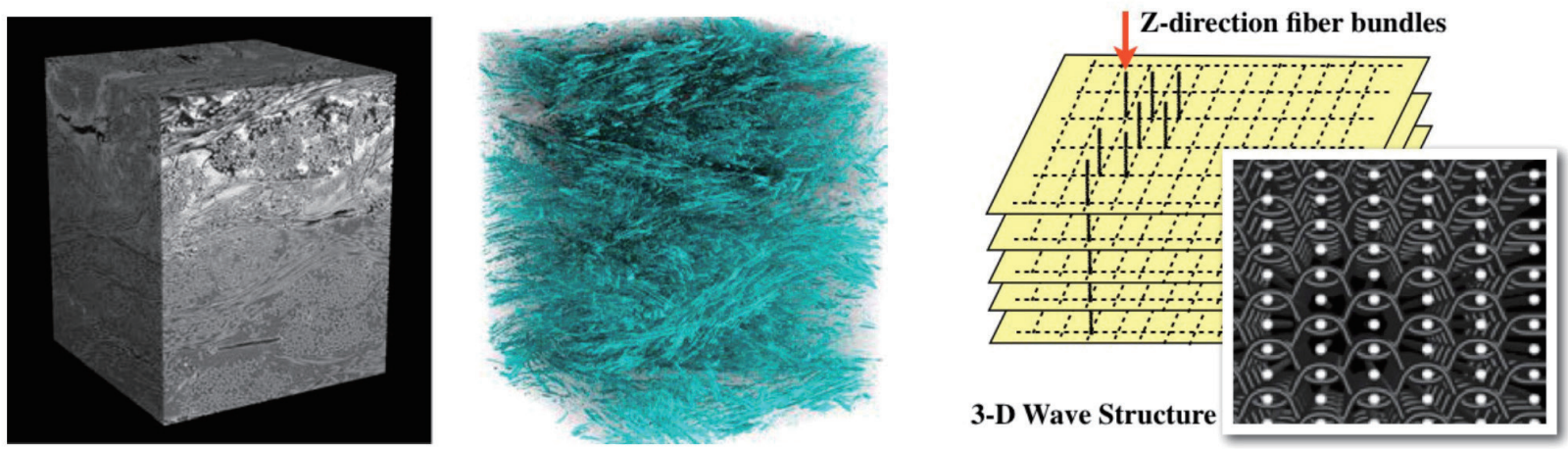

Fig. 3. Distribution of the closed-pore in the pyrolysis layer in the clothlayered ablator (Image processed from 3-D X-ray tomography data taken in SPring-8).

Fig. 4. Schematic view of the conventional 3- dimensional ablator and the 3-D woven (3-D wave-structure) lightweight ablator.

entries are not desirable from the down-range perspective. On the other hand, reducing the ballistic coefficient of the capsule is advantageous for decreasing heatflux under the constraints of high entry velocity and small weight allocation. Table-2 shows total heatflux characteristics with parameters of the nose radius and the front surface area in hayabusa similar shape and weight capsule with $16.5 \mathrm{~kg}$ weight at FPA of $10.3^{\circ}$ and $14.8 \mathrm{~km} / \mathrm{s}$ entry speed. The capsules with nose radius of 0.24 meter and diameter of 0.5 meter or larger can satisfy the heatflux requirement below $15 \mathrm{MW} / \mathrm{m}^{2}$. The lightweight ablator is necessary for the low ballistic coefficient capsule.

\section{Ligbtweight Ablator}

\subsection{3-D lightweight ablator}

According to the authors' previous studies ${ }^{5)}$, insertion of the fabric bundles in Z-direction of the ablator material (perpendicular to the prepreg plane) proved to be effective for reducing delamination and recession rate during the high heatflux environment. Because the process of the fiber bundles insertion was not suitable for automatic manufacturing, development study on the ablator did not make much progress until the innovative weaving process was proposed in 2013, which was outcome of the fusion collaboration between Japanese conventional textile technology and the JAXA's TPS technology: Three dimensional carbon fiber structure was successfully manufactured automatically with a conventional weaver machine, which can provide as long as required within limited maximum width correspondent to the weaver machine width.

Ablator with 3-D structure is thought to exhibit excellent allowable stress both in the in-plane and out-of-plane, while the conventional cloth-layered one only in in-plane. Because the fiber bundle is good thermal conductor compared with the matrix itself, the thermal decomposition starts along the fiber bundles at the beginning of the decomposition in the pyrolysis layer ${ }^{5)}$, as shown in X-ray tomography of the ablator after the heating test (Fig. 3). Thus, Z-direction fiber bundles are advantageous for avoiding delamination, because it can release pyrolysis gas pressure through the open pores generated along the

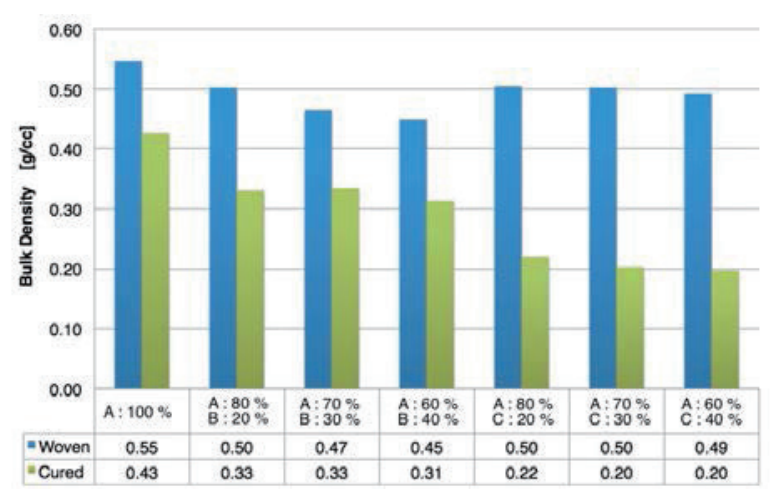

Fig. 5. Thermal properties of the 3-dimensionally woven ablator: A, B, C is a given type of fiber though not published here. Density after woven and cured process are tabulated.

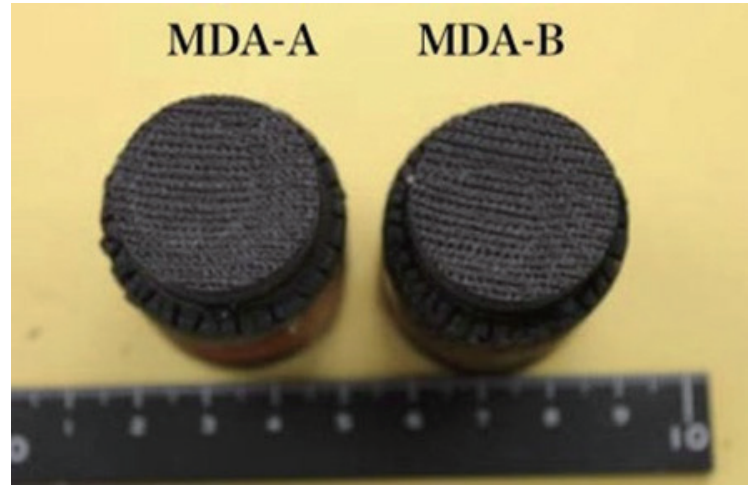

Fig. 6. Surface of 2 samples of the 3-dimensionally woven lightweight ablator after heating test $(12 \mathrm{MW} / \mathrm{m} 2-30 \mathrm{sec})$ : No damage (such as surface delamination, cracks) are found.

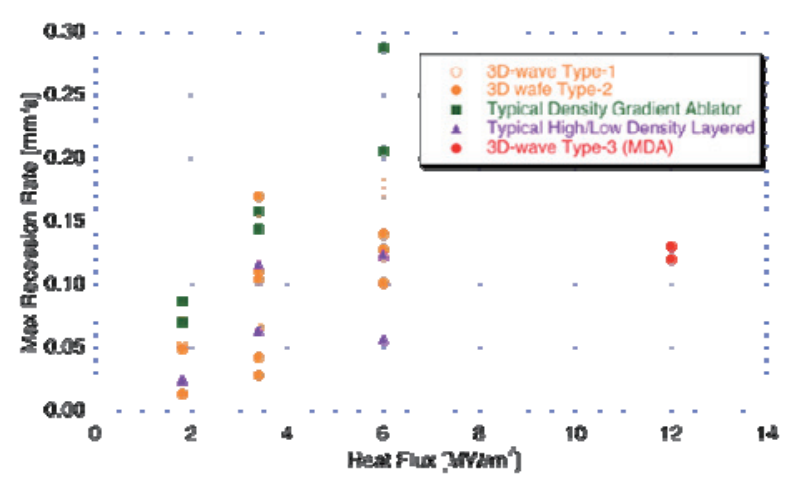

Fig. 7. Recession Characteristics with paratmeters of the heatflux. 
bundles. The present 3-D ablator has adopted "3-D wave structure" such that no fiber bundles penetrates from the surface to the back side but they connect every second layers to another, which realized weaver machine manufacturing as schematically shown in Fig.4. The fiber bundles are woven together with light-weight-assist fibers, which help controlling intervals among main fiber bundles and disappear leaving pores at curing process leaving appropriate porosity for lightweight design. By controlling the size or number of the lightweight-assist fiber bundles, 3-D carbon structure with bulk density ranging from 0.2 to $0.4 \mathrm{~g} / \mathrm{cm}^{3}$ is fabricated at completion of cure process as shown in Fig. 5. The density of 3-D wave structure ablator is controllable by adjusting tensile stress, size and the fraction of the light-weight-assist fibers.

\subsection{Performance characterization of $3 \mathrm{D}$ ablator}

The 3-D woven lightweight ablator with bulk density of $0.55 \mathrm{~g} / \mathrm{cc}$ has undergone a series of arc-heating tests and exhibited excellent recession characteristics of $0.12 \mathrm{~mm} / \mathrm{s}$ under the $12 \mathrm{MW} / \mathrm{m}^{2}$ arc-heating tests without remarkable damages seen on the surface as shown in Fig. 6. Though the density of the ablators and other arc-heating conditions than heatflux are different, and performance comparison are not quantitative in its exact meaning, the recession rate of several types of ablators are plotted as a function of the heatflux as shown in Fig.7, though data of the ablators with different density are plotted without explicit description.

\section{Development of Crushable Material}

\subsection{Space missions and landing-shock absorption}

The crushable structure realizes chuteless landing by absorbing landing shock energy and protects the instrument modules against the landing shock within a prescribed deceleration level, which technology is advantageous for secure decent system in that ignition electronics, parachutetriggering sensors, and triggering-control logic circuits etc. are no longer required.

Table-2 shows landing approach consideration to be achieved by adoption of the crushable structure for small capsules or probes in space missions. The ballistic coefficient of the Hayabusa capsule is about $154 \mathrm{~kg} / \mathrm{m}^{2}(\mathrm{Cd} \sim 0.85 @$ Mach 0.5) in the subsonic region, the terminal velocity is estimated to be about $48 \mathrm{~m} / \mathrm{s}$ as shown in Fig. 8. The terminal velocity varies from about 30 to $50 \mathrm{~m} / \mathrm{s}$ according to design of the capsules. In case that the landing shock absorption in this velocity level is realized by crushable structure, the several missions will have alternative approach on the surface of the planet, which is of great use for secure landing and fail-safe designing against the landing systems' malfunctions.

\subsection{Design and requirements for crushable material} deceleration constraints

Requirements for the crushable material that enables chuteless capsule designing is summarized as follows;

1) to have appropriate transfer function of such that suppresses the shock response spectrum be within subsystems' requirements.

2) displacement is negligible against the static load during the long orbital flight.

3) performance degradation negligible in a vacuum and radiation condition.

4) made of material free from outgassing and solid particle scattering.

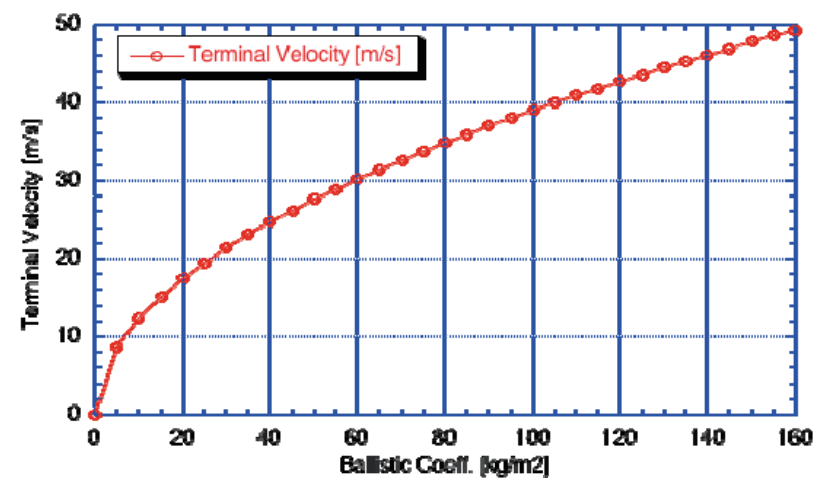

Fig. 8. Terminal velocity vs. ballistic coefficient characteristics in the earth environment.

Table 2. Landing approach consideration to be achieved by adoption of the crushable structure for small capsules and probes.

\begin{tabular}{|c|c|c|c|}
\hline & Earth, Venus & Mars & Moon, Io, Enceladus (Saturn II) \\
\hline Characteristics & $\begin{array}{l}\cdot \text { Middle Level Gravity } \\
\cdot \text { Dens Atmosphere }\end{array}$ & $\begin{array}{l}\text { - Middle Level Gravity }(0.38 \mathrm{G}) \\
\text { - Low-Dens Atmos. }\left(0.01 \mathrm{~kg} / \mathrm{m}^{3}\right)\end{array}$ & $\begin{array}{l}\text { - Small Gravity }(<0.18 \mathrm{G}) \\
\cdot \text { No Atmosphere / Extre. Low Dens Atmos, }\end{array}$ \\
\hline Approach & $\begin{array}{l}\text { Chuteless } \\
\text { + Landing-shock Absorption }\end{array}$ & $\begin{array}{l}\text { Parachute } \\
\text { + Landing-shock Absorption }\end{array}$ & $\begin{array}{l}\text { delta-V for Zero Orbital Velocity \& Freefall } \\
\text { +Landing-shock Absorption }\end{array}$ \\
\hline $\begin{array}{l}\text { Landing } \\
\text { Speed }\end{array}$ & $\begin{array}{r}40 \mathrm{~m} / \mathrm{s} \text { (Earth) } \\
6 \mathrm{~m} / \mathrm{s} \text { (Venus) }\end{array}$ & $\begin{array}{r}272 \mathrm{~m} / \mathrm{s} \text { (w/o Chute) } \\
42 \mathrm{~m} / \mathrm{s} \text { (w/ Chute) }\end{array}$ & $\begin{array}{c}100 \mathrm{~m} / \mathrm{s} \text { Moon }(\mathrm{H}=3 \mathrm{~km}) \\
<40 \mathrm{~m} / \mathrm{s} \text { Io }(\mathrm{H}=3 \mathrm{~km}) \\
<40_{\mathrm{m} / \mathrm{s}} \text { Enceladus }(\mathrm{H}=10 \mathrm{~km})\end{array}$ \\
\hline
\end{tabular}



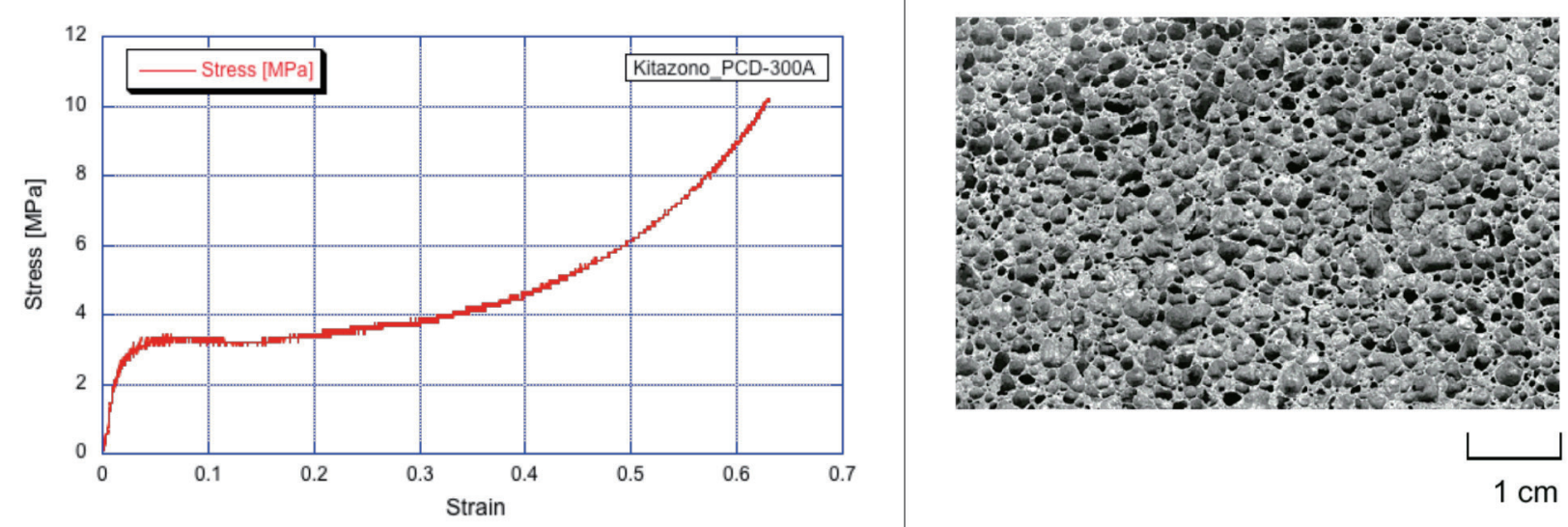

Fig. 9. Typical stress vs. strain characteristics of the cellar-metal crushable material. (measured data)

5) (desirable) radio-wave transparent material.

Cellular porous metal is one of the promising candidate for the crushable material satisfying requirements listed above except 5).

The cellular-metal crushable material with constant plateau stress ${ }^{7), 8)}$ for certain ranges of the strain (Fig. 9, for example) is advantageous to restrict effectively the consequent deceleration rate within a designed value, which has been investigated and tested for use in the compact capsule after the long-term missions.

In order to have foresight in the further design process, crushable material has been modeled as shown in Fig. 10. the Applying the deceleration level $a_{\max }$ acceptable for the onboard instrument, the maximum plateau stress $\sigma_{p}$ is uniquely determined to be

$$
\sigma_{p}<\sigma_{p, \max }=\frac{m}{A} a_{\max }
$$

where $\mathrm{m}$ is summation of the instrument mass and crushable structure mass, and A is the bottom area. As it will be described in the following section, $\sigma_{p}$ in Eq. (1) is safeside approximation at its maximum value because the squashed crushable material during the process of energy absorption does no longer behave as inertia mass, which acts to reduce the instantaneous deceleration compared with the initial value. Table-3 shows maximum stress examples for 2 types of $\mathrm{m} / \mathrm{A}$ value: "the crushable ball" is the test model to be discussed in the following sections. The nominal landing shock of the Hayabusa SRC with deployed parachute was estimated to be $3,000 \mathrm{G}$ based on several drop tests onto simulated typical desert ground. The Hayabusa-1 SRC onboard instruments together with the sampler sealing mechanism designed under the conditions actually survived landing shock at the recovery in 2010. Taking account of the actual achievement, thus, the maximum acceleration $\mathrm{a}_{\max }$ has been determined to be 3,000G at the present target.

\section{Volumetric Energy Absorption}

When the energy is absorbed only in the plateau region and the amount absorbed in the elastic region is negligible, the following approximation is available :

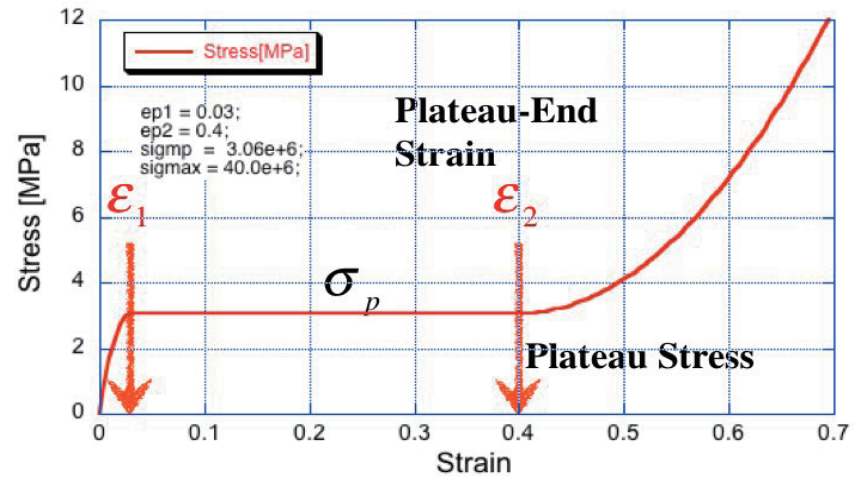

Fig. 10. Numerical modeling of the stress vs. strain.

$$
\frac{1}{2} m_{0} v_{0}^{2}=V_{0} \int \sigma d \varepsilon \approx \sigma_{P} \varepsilon_{2} V_{0}
$$

In order to absorb the total shock energy exclusively in the plateau region, the allowable initial material volume $V_{0}$ at minimum $V_{0, \text { min }}$ is expressed as

$$
V_{0}>V_{0, \min }=m_{0} v_{0}^{2} / 2 \sigma_{p} \varepsilon_{2}
$$

The larger $\varepsilon_{2}$ is desirable for minimizing the material volume $\mathrm{V}_{0}$ at a given terminal velocity and plateau stress.

The minimum plateau-end-strain $\varepsilon_{2}$ is also determined under the condition that the landing shock energy is completely absorbed within the plateau region:

$$
\varepsilon_{2}>\varepsilon_{2, \min }=m_{0} v_{0}^{2} / 2 \sigma_{p} V_{0}
$$

\section{Thickness of the Crushable Material}

In order to absorb the shock energy efficiently within a given acceleration constraint, the minimum thickness is also expressed as

$$
t=V_{0} / A
$$

By substituting Eq. (1) and (3) for (5), the minimum thickness is expressed as

$$
t=\frac{m_{0} v_{0}^{2}}{2 A \sigma_{p} \varepsilon_{2}}=\frac{1}{2} \frac{m_{0}}{m_{P I}} \frac{v_{0}^{2}}{a_{\max }} \frac{1}{\varepsilon_{2}}
$$


Trans. JSASS Aerospace Tech. Japan Vol. 14, No. ists30 (2016)

Table 3. Required plateau stress (in case $\mathrm{a}_{\max }=3000 \mathrm{G}$ ).

\begin{tabular}{|l|c|c|c|c|}
\hline & PI Weight $: \mathrm{m}$ & Instrument Area $: \mathrm{A}$ & $\mathrm{m} / \mathrm{A}$ & $\sigma_{\mathrm{p}}$ \\
\hline Hayabusa & $6 \mathrm{~kg}$ & $\begin{array}{c}282 \mathrm{~cm}^{2} \\
(138 \times 204 \mathrm{~mm})\end{array}$ & $212.7 \mathrm{~kg} / \mathrm{m}^{2}$ & $6.3 \mathrm{MPa}$ \\
\hline Future Capsule $(\mathrm{A}=2 \mathrm{~A})$ & $6 \mathrm{~kg}$ & $564 \mathrm{~cm}^{2}$ & $106.3 \mathrm{~kg} / \mathrm{m}^{2}$ & $3.13 \mathrm{MPa}$ \\
\hline Crushable Ball & $50.5 \mathrm{~g}$ & $4.9 \mathrm{~cm}^{2}(\varphi 25 \mathrm{~mm})$ & $103.1 \mathrm{~kg} / \mathrm{m}^{2}$ & $3.03 \mathrm{MPa}$ \\
\hline
\end{tabular}

Table 4. Minimum Volume $\left(\sigma_{\mathrm{p}}=\sigma_{\mathrm{p}-\max }\right.$, Plateau End $\left.=60 \%\right)$.

\begin{tabular}{|c|c|c|c|c|c|c|}
\hline & PI Weight & $\sigma_{\mathrm{p}}$ & $\mathrm{V}_{0}$ & $\mathrm{E}[\mathrm{J}]$ & $\mathrm{V}_{\text {min }}$ & thickness \\
\hline Hayabusa & $6 \mathrm{~kg}$ & $6 \mathrm{MPa}$ & $48 \mathrm{~m} / \mathrm{s}$ & 6912 & $1.92 \mathrm{~L}$ & $68 \mathrm{~mm}$ \\
\hline Future Capsule (A=2A) & & $3 \mathrm{MPa}$ & $30 \mathrm{~m} / \mathrm{s}$ & 2700 & $1.5 \mathrm{~L}$ & $26 \mathrm{~mm}$ \\
\hline Crushable Ball & $50.5 \mathrm{~g}$ & $3 \mathrm{MPa}$ & $30 \mathrm{~m} / \mathrm{s}$ & 22.7 & $0.0126 \mathrm{~L}$ & $25.7 \mathrm{~mm}$ \\
\hline
\end{tabular}

Thus, the larger plateau-end strain is desirable for minimizing the thickness for effective shock energy absorption.

Table-4 shows calculated values for each parameters in case that the larger plateau-end strain $\varepsilon_{2}$ is assumed to be $60 \%$ to the initial total length. It is apparent that the accommodation of the crushable material with thickness of 68 $\mathrm{mm}$ in the Hayabusa capsule is not feasible while thickness of $26 \mathrm{~mm}$ material in case that $\mathrm{m} / \mathrm{A}$ designed to be half of Hayabusa is feasible for accommodation.

\subsection{Landing-shock simple analysis}

In order to study essential deceleration characteristics of the crushable material at landing impact before the actual demonstration experiment, simple analysis has been carried out:

The squashed zone is formed at the bottom of the crushable material, and the density is assumed to be constant inside each region as shown in Figures $10 \& 11$. The deceleration can be estimated based on the following equations.

$$
\begin{gathered}
m=m_{c}+m_{p}-m_{s q} \\
\frac{d m}{d t}=-\frac{d m_{\text {crushed }}}{d t}=-2 A \rho_{c} \frac{d y}{d t} \\
m \frac{d v}{d t}=-v \frac{d m}{d t}-\sigma \cdot A(y) \\
\frac{d y}{d t}=v \\
\frac{\sigma \varepsilon}{d t}=\frac{-1}{A V_{0}}\left[\frac{1}{2} v^{2} \frac{d m}{d t}+m v \frac{d v}{d t}\right]
\end{gathered}
$$

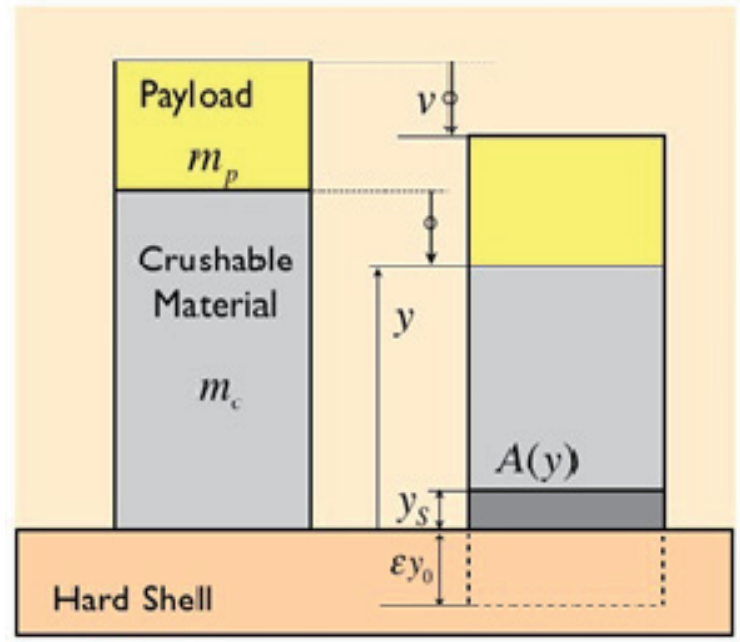

Fig. 11. Shock deceleration analysis modeling: the hard-shell and the payload are assumed to be rigid and the squashed region is designated in dark gray.

where A: Area, $\mathrm{m}$ : total inertia mass, $\mathrm{m}_{\mathrm{c}}$ : mass of crushable material, $\mathrm{m}_{\mathrm{p}}$ : mass of payload, $\mathrm{y}:$ displacement, $\mathrm{v}$ : velocity, $\varepsilon$ : Strain, $\sigma:$ stress, $\rho_{c}$ : density of crushable material, and $\mathrm{A}$ : area.

In the present analysis, the ground property is assumed to be infinitesimally hard, which means the landing energy is solely absorbed in the crushable material and, therefore, this assumption is in the safety-side design. According to the measurement of the diameter of landing impact mark of the Hayabusa SRC, left on the Australian desert, the ground is estimated to be $30 \mathrm{MPa}$ plateau stress equivalent and to absorb about $20 \%$ of the total landing energy, which is considered to be margin at the present feasibility study phase.

Figure 12 shows a result of the landing shock analysis with initial velocity of $30 \mathrm{~m} / \mathrm{s}$ and initial mass-to-area is 70 $\mathrm{kg} / \mathrm{m}^{2}$ (Cellular-metal properties were already modeled in Fig. 10). The overall impact process is completed within about $1.1 \mathrm{~ms}$. The deceleration rate overshoots at the beginning of the process and soon starts to decrease according 

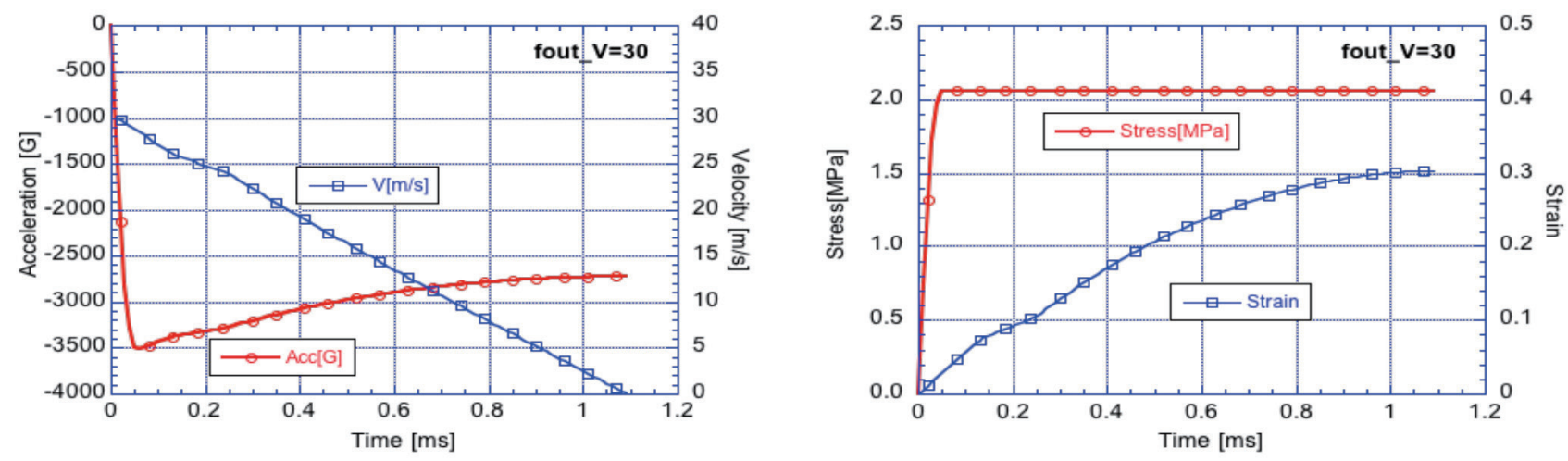

Fig. 12. A Result of the Landing Shock Analysis with initial velocity of $30 \mathrm{~m} / \mathrm{s}$ and initial mass-to-area is $70 \mathrm{~kg} / \mathrm{m}^{2}$.

to the decrease of the inertia mass due to squash of the crushable material as predicted. Though this simple analysis is useful as baseline screening of the material, analysis of the propagating shock wave is required for estimating its effect on the maximum deceleration.

\subsection{Landing impact tests by ballistic-range}

In order to check validity of the analysis and extracting other issues concerned with crushable landing impact, the landing impact test was planned by using a small test model in the ballistic range in JAXA Kakuda Space Center. The crushable ball (test model) ejected from the ballistic range impacts directly on the impact target at a given velocity after mili-second free-flight. The experiment configuration is schematically shown in Fig. 13. A concrete block with $600 \mathrm{~mm} \times 600 \mathrm{~mm}$ front area and about $500 \mathrm{~kg}$ in weight is fixed to the floor as an impact target. The crushable ball made mainly with stainless steel with built-in crushable material, acceleration sensor, and the data logger is shown in Fig. 14. The sensor module is mounted in the outer forebody shell at the top of the crushable material, the weight and the bottom area of which are designed to simulate $\mathrm{m} / \mathrm{A}$ of that of the future target capsule as were already shown in Table-3 and 4. The ballistic range facility have capability to fly test models of max. $120 \mathrm{~mm}$ diam. (including sabot) at velocity of up to Mach 2 .

Figure 15 shows the landing impact test model in the instance just before the impact on the target (captured from high-speed video): pair of the teflon sabot are separated automatically by aerodynamic force forward both left and right side. The impact velocity up to $30 \mathrm{~m} / \mathrm{s}$ has been accomplished according to the measurement by the time-of-flight laser velocimetry. Though the extent of the total strain of the crushable material exhibited good agreement with predictions, data logger failed to record the deceleration, which is supposed to be caused by insufficient potting to the logger boards. At the moment, judging from the impact velocity and the squashed crushable material, concept of the chuteless capsule is feasible except detailed design issues. For the sake of actual impact demonstration with measured deceleration rate, further improvement on data acquisition systems is planned by the middle of 2015 .

\section{High-speed Compact Capsule Designing}

As was described in the previous sections, entry capsules with small ballistic coefficient generally reduce the maximum heat flux by significant degrees even at the entry velocity over $14 \mathrm{~km} / \mathrm{s}$. The crushable structure realizes chuteless landing by absorbing landing shock energy and protects the instrument modules against the landing shock within a prescribed level. Taking account of the state-of-the-art technologies of the lightweight ablator and the crushable structure, the authors has tentatively designed a compact capsule for high-speed entry missions.

Table-5 shows a design example of high-speed compact entry capsule enhanced by lightweight ablator and crushable structure. The weight allocation to the capsule is assumed to be $16.5 \mathrm{~kg}$, same as that of Hayabusa SRC. Development of the lightweight ablator has several uncertainty, the risks in which was calculated on weight margin of $1.2 \mathrm{~kg}$.
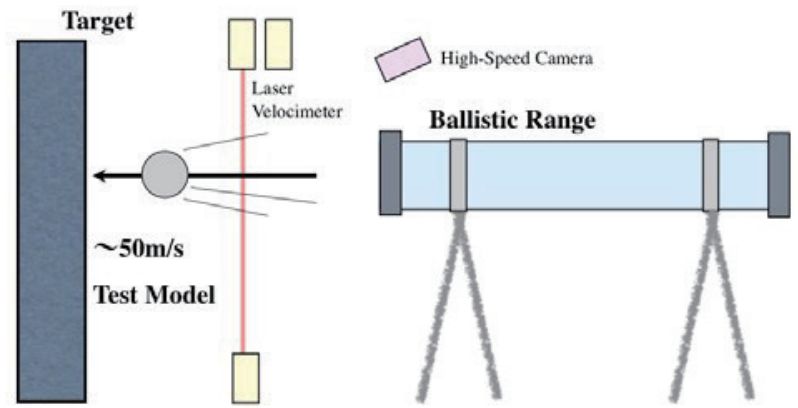

Fig. 13. A schematics of the experimental configuration of the metalball impact test through the ballistic range (JAXA/Kakuda).

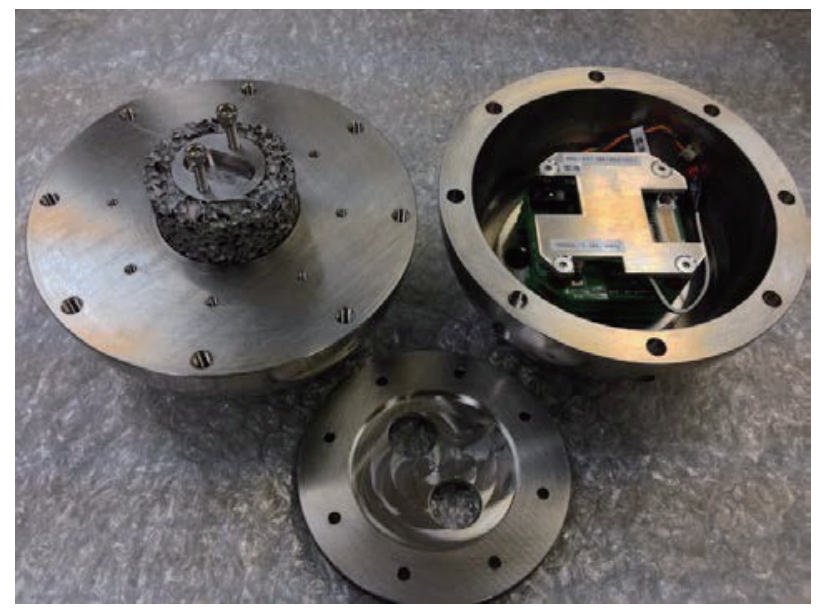

Fig. 14. The crushable-ball for the ballistic range impact test : An example of the crushable material is mounted in the center of the forebody shell (upper left in the photo). The data-logger is on the bottom of the aftbody shell (upper right). 


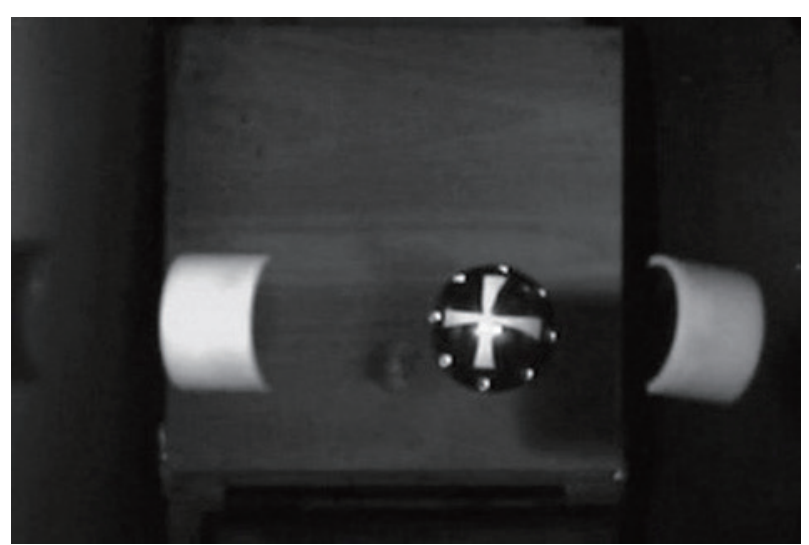

Fig. 15. Landing impact test model at the instance just before the impact on the target plate (captured from high-speed video) : a pair of the teflon sabot are separated automatically forward both left and right side by the aerodynamic force.

Table 5. A design example of high-speed compact entry capsule enhanced by lightweight ablator and crushable structure.

\begin{tabular}{|c|c|c|c|}
\hline & & Hayabusa & New Capsule \\
\hline \multirow[t]{5}{*}{ Capsule } & Structure & 2250 & $\leftarrow$ \\
\hline & Heatshield & 8915 & $\begin{array}{c}6700 ※ \varphi 50 \\
\text { +Risk Margin: } 1200 \mathrm{~g}\end{array}$ \\
\hline & $\begin{array}{l}\text { Onboard } \\
\text { Electronics }\end{array}$ & 2248 & \\
\hline & Pyro. Devises & 1070 & \multirow{2}{*}{$\begin{array}{l}\text { Crushable Structure } \\
(\rho=02) \quad 1830 \\
\text { (Margin icluded) }\end{array}$} \\
\hline & Parachute & 760 & \\
\hline $\begin{array}{l}\text { Sample } \\
\mathrm{r}\end{array}$ & & 1300 & $\leftarrow$ \\
\hline \multicolumn{2}{|c|}{ Capsule Flight Mass } & $16.5 \mathrm{~kg}$ & $16.5 \mathrm{~kg}$ \\
\hline \multicolumn{2}{|c|}{ SEP Mechanism } & 3200 & $\leftarrow$ \\
\hline
\end{tabular}

\section{Conclusion}

In order to sustain and extend the privilege on the field of the high-speed compact sample return capsule acquired through the development of the Hayabusa-series, the highspeed compact entry capsule is one of the key technologies to accomplish high-energy space exploration missions such as sample return from bodies beyond Mars. The present study has shown a conceptual design of the high-speed compact entry capsule enhanced by state-of-the-art technologies of the lightweight ablator and the crushable structure. The lightweight thermal protection ablator is very advantageous for reducing the ballistic coefficient. Three-dimensionally woven lightweight ablator has exhibited excellent recession characteristics with recession rate of $0.12 \mathrm{~mm}$ under the 12 $\mathrm{MW} / \mathrm{m}^{2}$ arc-heating tests. The crushable structure realizes chuteless landing by absorbing landing shock energy and protects the instrument modules against the landing shock within a prescribed deceleration level. According to the impact tests at velocity of $30 \mathrm{~m} / \mathrm{s}$ with cellular-metal material exhibited the predicted displacement and analysis showed feasibility of using cellular-metal material for the landing energy absorption of the compact capsule.

\section{Acknowledgements}

We are highly indebted to Mr. Masayuki Kitamura for his great effort in manufacturing ablator material in the present research.

\section{References}

1) French, K. E.: Parachute and Cushion Landing System, J. Spacecraft \& Rockets, 3 (1966), pp. 1133-1134.

2) Lisa Peacocks, et. al.: Marco Polo-R: Mission and Spacecraft Design, IPPW-10, San Jose, 17-21, June, 2013.

3) Yamada, T., et. al.: $3 \mathrm{H} 04$ Technical issues on high-speed entry missions, 57th JSASS Space Science \& Tech. Lecture Meeting, Yonago, Japan, 2013.

4) Mori, O., Funase, R., et. al: IKAROS Extended Operation for Advanced Solar Power Sail Mission, Trans. JSASS, Aerospace Technology Japan, 12, ists29 (2014), pp.Tk_19-Tk_24.

5) Yamada, T., Ishida, Y., et al.: Development of High and Low Density Ablators for DASH-II and Future Reentry Missions, ISTS-2009-e-03, 2009

6) Hemez, F.: Predictive Modeling Assessment of a Crushable Foam Material, AIAA 2005-2387, 46th Structures, Dynamics and Material Conference, Austin, Texas, April, 2005.

7) Kitazono, K., et. al: Novel Strength Method of Closed-Cell Al forms, J. Material Processing Tech, 209 (2009), pp. 3550-3554.

8) Kitazono, K., et. al.: 2H08: Shock absorption mechanism of sintered aluminum fibers in SLIM spacecraft, 7th JSASS Space Science \& Tech. Lecture Meeting, Nagasaki, Japan, 2014.

9) Yamada, T., Tanno, H., Kitazono, K.: 2H15: Study on crushable structures for landing shock relaxation of small capsules, 7th JSASS Space Science \& Tech. Lecture Meeting, Nagasaki, Japan, 2014.

10) Tanno, H., Komuro, T., Ito, K.:Free-flight aerodynamic test with projectile-onboard recorder in a ballistic range, AIAA 2013-0475, 51st Aerospace Science Meeting, Jan. 2013,Texas. 